\title{
Human Health Vulnerability to Climate Variability: The Cases of Cholera and Meningistis in Some Urban Areas of the Far North Region of Cameroon
}

\author{
Sunday Shende Kometa ${ }^{1}$, Mathias Ashu Tambe Ebot ${ }^{1}$, Humphrey Ndi Ngala ${ }^{1} \&$ Amawa Sani Gur ${ }^{1}$ \\ ${ }^{1}$ Department of Geography, University of Buea, P.O. Box 63, Buea, Cameroon \\ Correspondence: Sunday Shende Kometa, Department of Geography, University of Buea, P.O. Box 63, Buea, \\ Cameroon. E-mail: chevalsk@yahoo.com
}

Received: August 20, 2012 Accepted: September 20, 2012 Online Published: February 27, 2013

doi:10.5539/jgg.v5n1p116 URL: http://dx.doi.org/10.5539/jgg.v5n1p116

\begin{abstract}
Vector-borne diseases and their incidence in the northern Cameroon particularly the Far North Region have been recurrent and are on the increase. This paper assesses the impact of climate variability on the health of the population of the Far North Region of Cameroon which is characterised by a tropical semi-arid climate in the vicinity of the Lake Chad. Secondary data sources (Epidemiologic, climatic, ecologic, socio-economic data), questionnaires, interviews and focus group discussions provided relevant data. The paper examines the relationship between the outbreak of diseases and variations in some climatic elements. It highlights the relationship that exists between the direct effects of climate variations and the development of vector-borne diseases and their effect on human health. The results reveal a strong positive correlation between changes in the climatic elements and the incidence of vector-borne diseases particularly cholera and meningitis. The study makes proposals on ways of militating against the impact of vector-borne diseases on human development in the region.
\end{abstract}

Keywords: climate variability, vulnerability, vector-borne diseases, human health, adaptation

\section{Introduction}

The beginning of the second half of the Twentieth Century was a turning point in the process of urbanisation in most Third World countries in general and the Sub-Saharan African countries in particular. The urban population in this region of the world increased from less than $20 \%$ at the beginning of this period to about $50 \%$ today (WHO, 2005). This unprecedented rate of urbanisation has been associated with the increasing concentration of people in cities and significant transformation of the urban landscape, with the emergence of structures and activities that contribute to the modification of climate. Urban features like industrialisation, transportation, emerging rise concrete structures and other activities in urban centers have contributed to the absorption and release of heat energy and also, heat generated from the increasing concentration of population are all at the origin of present day trend in climate change which is being manifested through global warming. The increasing importation of second-handed cars in the cities of developing countries has increased traffic density, enhancing the generation of carbon monoxide, which is a major greenhouse gas. In recent years, human activity has been identified as a significant factor in global climate variability. According to the Inter-Governmental Panel on Climate Change (IPCC), there is substantial evidence to the fact that anthropogenic activities have become a factor of increasing importance in climate change (Cunningham \& Saigo, 2001).

Uncontrolled city expansion with the occupation of disaster-prone zones has exposed the urban population especially those in squatter settlements to the negative effects of hazards from climatic excesses such as floods, landslides and epidemics. The population of Cameroon rose from 7,663,246 in 1976 to 19.4 million in 2010 and the rate of urbanisation witnessed a remarkable increase from $37.9 \%$ to $48.8 \%$ between 1987 and 2005 . It is also worth noting that the rate of urbanisation was only $28.1 \%$ in $1976\left(3^{\text {rd }}\right.$ Cameroon General Population and Housing Census of 2005). The attendant consequences therefore have been the development of slums. Furthermore, many high-rise concrete flats have emerged in these cities alongside heat-generating activities. The cities have thus, become microcosms of global warming. The disposal of effluents into nearby streams and rivers easily result in pollutants spilling over into homes, farmlands, and streets, increasing the exposure of the urban populations to pathogenic substances after flooding from intense rainstorm. 
The last ten years have recorded an increase in the number of reported cases for some major water-borne diseases in Cameroon. Existing data reflects the occurrence of outbreaks of cholera and meningitis during the periods of excesses in climatic elements such as rainfall, temperature and humidity. The coincidence between these outbreaks and the months of high rainfall and temperature excesses seems to suggest the effect or control of long-term variations in climate. It is also worth noting that the outbreaks of these diseases are commonplace for the increasingly urbanized regions. This paper therefore, focuses on the pattern of cholera and meningitis outbreaks in the Far North Region of Cameroon and the vulnerability of the urban populations to this climate-induced health hazards.

Furthermore, based on the revelation from our primary and secondary data, it attempts to illustrate the relationship between diseases outbreak and fluctuations in the specific elements of climate. Even though such correlation between climate variability and human health hazards are still receiving much attention in research on a global scale, specific diagnoses of the causes of the problem at the local and regional scale will still serve a very reliable beginning in any effort to put the problems under control for specific problem regions. This is important if the Government needs to deploy or emphasise the redeployment of any aggressive measure through the prompt allocation of medication, health personnel, relevant infrastructures and prevention programmes. The basis of such across-the-board measures should be the clear revelation of a process and effect relationship, its magnitude and geographic area. Apart from illustrating the connection between the fluctuations in the climatic elements and the urban health-related hazards in the study area, the present paper where necessary intends to propose recommendations for long-term solutions in the control of cholera and meningitis.

\section{Study Area}

Cameroon covers a surface area of $475,442 \mathrm{~km}^{2}$. The landmass stretches from the Gulf of Guinea, extending from latitudes $2^{\circ}$ and $13^{\circ}$ north of the equator and longitudes $8^{\circ}$ and $16^{\circ}$ east of the Greenwich Meridian. This vast territory with a rich mosaic of diverse climate, geology, vegetation and cultures all reflected on its expansive landmass is considered to be 'Africa in miniature'. The relief consists of lowlands, undulating plateaux and mountain ranges. Temperatures are very contrasting, as one moves from the equator towards the tropic of cancer. The southern part of the country with its equatorial rain forest experiences high temperatures between $27^{\circ} \mathrm{C}$ and $37^{\circ} \mathrm{C}$. This area is generally humid with long periods of rainfall. The annual rainfall in this region is about 4,060 $\mathrm{mm}$. Temperatures towards the northern regions are higher with a larger range. In the semi-arid and arid north, the annual rainfall is about $850 \mathrm{~mm}$ around Maroua and Kousseri and the average temperature is $37^{\circ} \mathrm{C}(\mathrm{Neba}, 1998)$.

The Far North Region is located in the Sudano-Sahelian zone. According to the Cameroon Statistical Year Book of the year 2005 the Far North has a population of 3,575,288 and Maroua the capital city of the Far North Region has a population of about 340,000 inhabitants. The population of this city is expected to have increased significantly due to the rapid rate of urbanization. The Sudano-Sahelian zone is a zone of ecological transition between the densely forested and savanna landscapes on the one hand and the hot arid landscape of the Sahara desert, with its southward transition into the Sahel zone on the other hand. Yearly rainfall in this tropical semi-arid zone is about $800-900 \mathrm{~mm}$ and generally comes from July to October with the other 8 months dry. The low rainfall is due to the effects of continentality and the great distance from the Atlantic Ocean, as well as its proximity to the Saharan anticyclone and the continental trade winds that blow over the region. The trade winds compounded with the high mean annual temperature of $37^{\circ} \mathrm{C}$ have had a strong desiccating effect on the environment. Atmospheric humidity is therefore low. Furthermore, the dominance of ephemeral rivers and the Southward encroachment of the desert are clear indicators of the increasing physiological discomfort arising from thermal stress. This predisposes people to a variety of diseases as over $70 \%$ of people in the city are likely to be uncomfortable. Besides the climatic predisposition, it is equally important to note that over $70 \%$ of the illnesses in the Far North Region are directly or indirectly associated with poor water supply and sanitation. This latter assertion is a reflection of the accelerated and uncontrolled urbanization that increases the level of vulnerability of urban dwellers, especially the poor to diseases related to climate variations.

\section{Materials and Methods}

200 questionnaires were prepared and distributed to residents in some settlements in the Far North Region -Roua, Mora, Bourha, Mogode, Hina, Kolofat and Maroua. Interviews were also conducted with some local authorities and members of the department of health. From the questionnaires and focused-group discussions with a sample of the local population, $55 \%$ of the respondents noted that there has been a change in the climatic elements. They specified either higher rainfall or more incidence of flooding. 30\% said there has been no significant variation in rainfall and blamed the recurrent occurrence of cholera on poor sanitation and hygiene, pollution and lack of adequate medical facilities. $15 \%$ were not sure if rainfall amounts are more or less than before. With respect to 
temperature, $52 \%$ of the respondents said the generally high temperatures for the Far North Region have gone higher. $35 \%$ acknowledged no significant changes in the temperature while $12 \%$ were not sure if there had been any change in the temperature. In terms of the incidence of cholera, $64 \%$ of the respondents said they now see or get informed on more cholera cases in the region than before. $18 \%$ said there are less cases of cholera in the region while $10 \%$ said the number for observed cases has not really changed. $8 \%$ of the respondents were not sure. Considering meningitis, $40 \%$ observed more incidences in the reported cases, $35 \%$ said it had stayed the same; $15 \%$ said there was a drop and $10 \%$ were not sure of the trends.

Apart from the perception of the respondents, hospital sources generally indicate an increase in the incidence of epidemic cholera and meningitis. The issue of poor sanitation, poor waste disposal and management also appear to be major contributors to the incidence of cholera and meningitis. From focused group discussions and information from municipal and public health authorities, it was revealed that the poor and the less privileged were the most affected by the cholera epidemic given that whenever there is contamination of their potable water sources, it leaves them with very little or no options for alternative water supplies. The wealthy and those with reliable sources of income on the other hand are served with reliable water facilities and even have the option to go for bottled water. There were no distinctions in terms of socio-economic class and the incidence of meningitis. In other words, no socio-economic group was more vulnerable than the other. Meteorological data from 1984 to 2000 was collected from the meteorological stations in Maroua and Kousseri (Table 1). The data collected included mean monthly temperatures, precipitation, relative humidity, days with precipitation, solar radiation and insolation (hours of light). The Ministry of Public Health through the public hospitals, health centers, private hospitals and clinics and the International Federation for the Red Cross provided the epidemiologic data from 2004 to 2011. Socioeconomic data was obtained from the local councils.

\section{Results}

The Sudano-Sahelian climate of the Far North Region is one where July and August account for about $66 \%$ of the total yearly rainfall (Ndenecho \& Fonteh, 2010). With this climatic regime, the short wet season is followed by a long and severe dry season, during which streams and vegetation dry up. The dry season, which last, about 7 months for the entire region and the high rate of evaporation, exhaust the reserves of groundwater. For low-lying areas like the Chad Basin, the dry season is longer and more intense and the rainy season lasts for only about 3 months (Neba, 1999). The well-being and survival of plants and animals will be significantly compromised in an environment marked by considerable fluctuations in temperature and rainfall. Fluctuations in temperature results in variation in the timing of rainfall causing unexpected flooding in some areas and drought in others (Ayonghe, 2001). Furthermore, the trend in the net increase in mean annual temperature across Cameroon has been reported with Maroua $\left(0.23^{\circ} \mathrm{C}\right)$ being among the cities with the highest observed increases in temperature (Ayonghe, 2001).

The computed coefficients of variation (CVs) for rainfall (Table 1) for the period from 1985 to 2008 show quite high values from $20 \%$ to $27 \%$ for about two-third of the occurrences. The coefficient of variation with high values indicates years characterized by the alternation of extremes of very dry and very wet periods. Given the effect of the southward encroachment of the Sahara desert (on the Far North Region), the expectation is for a consistent rise in the rainfall variability figures in the northward direction. Consequently, Ngakfumbe (2001) points out that although the pattern of the mean annual rainfall variability over the country is not well defined, there is a clear progressive rise from latitude $7^{\circ}$ North toward Kousseri, with registered values of $26.5 \%$, the highest rise in this direction. The consequences of the severe irregularities in rainfall and temperature are flooding for some areas and droughts for most other areas in the Far North Region. The long and severe arid cycles and the resulting low atmospheric humidity will jeopardize the health and sustenance of plants, animals and humans.

The situation of major diseases outbreak in the Far North Region of Cameroon shows a pattern which generally suggest the influence of variability in climate. The patterns, in terms of outbreak and lethality rates are demonstrated for cholera and meningitis. The anomalies in global weather and climate have resulted in unpredictable weather patterns and excesses in the elements of rainfall, temperature and atmospheric humidity. With respect to the cholera epidemic for example, the first cases recorded according to the International Federation of the Red Cross (IFRC, 2009) and the Red Cresient were generally reported from Northern Cameroon and the Far North Region in particular, in September. In Cameroon, September is a rainy month and comes immediately after the wettest months of July and August. Furthermore, for the Far North Region, available data suggest a progressive increase in rainfall from 1984 to 2011 (Table 1). These recently frequent anomalies of excessive rainfall are expected to enhance and energise surface run-off and subsurface hydrological processes so that the contamination of natural sources of potable water through floods, erosion and cycles of deposition remain immediate issues for residents and municipal authorities to grapple with. 
Table 1. Average annual rainfall and temperature data for the Far North Region from 1984 to 2009

\begin{tabular}{lllll}
\hline Year & Rainfall & STDEV & Mean & CV (\%) \\
\hline 1985 & 688.2 & 168.8664 & 681.7 & 25 \\
1986 & 726 & 198.035 & 726.65 & 27 \\
1987 & 583.2 & 121.955 & 583.2 & 21 \\
1988 & 676.8 & 124.7177 & 835.9167 & 15 \\
1989 & 677 & 121.0311 & 676.733 & 18 \\
1990 & 611.2 & 140.7487 & 611.0833 & 23 \\
1991 & 836.9 & 151.7053 & 836.4333 & 18 \\
1992 & 750.1 & 174.5229 & 739.4667 & 24 \\
1993 & 716.8 & N/A & N/A & N/A \\
1994 & 934.5 & 177.2206 & 934.6333 & 19 \\
1995 & 741.1 & 175.0243 & 741.1167 & 24 \\
1996 & 750.6 & 185.7573 & 741.1833 & 25 \\
1997 & 768.9 & 196.0861 & 782.0167 & 25 \\
1998 & 785.7 & 146.7199 & 783.55 & 19 \\
1999 & 851 & 101.5114 & 858.85 & 12 \\
2000 & 742.1 & 181.8185 & 742.05 & 25 \\
2001 & 842 & 188.696 & 842.1333 & 22 \\
2002 & 635 & 131.0902 & 634.4167 & 21 \\
2003 & 831 & 123.2971 & 831.1667 & 15 \\
2004 & 637 & 162.4813 & 654.1667 & 25 \\
2005 & 824 & 165.53 & 824.8333 & 20 \\
2006 & 705 & 175.4857 & 776.0333 & 23 \\
2007 & 875 & 174.1279 & 8751667 & 20 \\
2008 & 856 & 134.8773 & 761.7167 & 18 \\
2009 & 860 & & & \\
\hline
\end{tabular}

N/A - Not available; STDEV - Standard deviation; CV - Coefficient of Variation.

The effect of high rainfall as a climatic facilitator in the incidence of cholera is further emphasized by the data recorded for cholera patients in the region from 2004 to 2011 (Table 2), which shows the only major cluster of cholera cases between May (the beginning of the rains) and October (the end of intense rains). This is consistent with the September 2009 cholera outbreak in some localities in the North and Far North Regions which appeared to have been due to the pollution of the Mobi water source, which originate in Nigeria and flows through Bourha in the Far North Region (IFRC, 2009). It is also worth noting that cases of the cholera epidemic were also recorded for the residential areas in Nigeria around the same water sources. The findings revealed fatality rates of $13 \%$ and $12 \%$ (IFRC, 2009) for the North and Far North Region respectively. Furthermore, in 2010, about 10,741 cholera cases were reported with 650 fatalities in Cameroon. Apart from the high amounts of rainfall, the high rates of population growth and urban expansion have introduced congested and unplanned residential landscapes in this region characterized by substandard facilities and the absence of potable water points. The absence of adequate waste disposal facilities and services accounts for the rampant disposal of domestic and human wastes within residential areas and at close proximities to natural water sources.

The recent outbreaks of epidemic cholera and fatalities are not uncommon for other regions of Cameroon. The WHO data from January to March 2011 also shows an overwhelming incidence of the diseases in the highly urbanized metropolitan Littoral and Centre Regions of Cameroon, with 254 and 687 cholera cases respectively (Regional Office WHO Cameroon, 2011).Out of 98 deaths for the entire country in 2011, the Littoral and Centre Regions recorded 34 and 43 deaths respectively indicating an overwhelming proportion for the national fatality level. Apart from emphasizing the provision of potable water and acceptable standards of hygiene for the majority 
of the urban poor, an equally imperative measure against the incidence of cholera should emphasize on environmental health, monitoring and alternative options for the mobilization of resources to inaccessible areas. Furthermore, findings from focused-group discussions blamed the deaths from cholera epidemic on the stigma associated with the disease. In other words, the participants noted that those who seem to manifest the initial symptoms are usually reluctant to go to any health unit as they fear they would immediately be isolated, abandoned and treated like sub-humans, once they are diagnosed with the disease. Consequently, most cases usually arrive the health centres late (only during the most advanced stages of the illness).

Table 2. Number of recorded cholera patients from 2004 to 2011 in the Far North Region of Cameroon

\begin{tabular}{|c|c|c|c|c|c|c|c|c|c|c|}
\hline \multirow[t]{2}{*}{ Month } & \multirow{2}{*}{$\begin{array}{c}\text { Mean Annual } \\
\text { Temperatures }\left({ }^{\circ} \mathrm{C}\right)\end{array}$} & \multirow{2}{*}{$\begin{array}{l}\text { Mean Annual } \\
\text { Rainfall (mm) }\end{array}$} & \multicolumn{8}{|c|}{ Recorded number of patients } \\
\hline & & & 2004 & 2005 & 2006 & 2007 & 2008 & 2009 & 2010 & 2011 (March) \\
\hline $\mathrm{J}$ & 38 & 0 & 0 & 0 & 0 & 0 & 0 & 0 & 0 & 0 \\
\hline $\mathrm{F}$ & 37.3 & 0 & 0 & 0 & 0 & 0 & 0 & 0 & 0 & 0 \\
\hline M & 41.5 & 0 & 0 & 0 & 0 & 10 & 09 & 48 & 98 & 50 \\
\hline A & 48.6 & 1.5 & 0 & 0 & 0 & 30 & 11 & 20 & 79 & - \\
\hline M & 45.7 & 34.3 & 4 & 2 & 1 & 60 & 22 & 102 & 58 & - \\
\hline $\mathrm{J}$ & 47.1 & 48.3 & 34 & 3 & 4 & 26 & 50 & 46 & 25 & - \\
\hline $\mathrm{J}$ & 43 & 127.7 & 241 & 6 & 1 & 23 & 08 & 48 & 29 & - \\
\hline A & 39.3 & 208.7 & 131 & 35 & 0 & 35 & 30 & 30 & 87 & - \\
\hline $\mathrm{S}$ & 37.7 & 79.3 & 33 & 1 & 0 & 72 & 68 & 72 & 133 & - \\
\hline $\mathrm{O}$ & 37.6 & 33.4 & 33 & 0 & 0 & 0 & 0 & 0 & 0 & - \\
\hline $\mathrm{N}$ & 38.2 & 0 & 0 & 0 & 0 & 0 & 0 & 0 & 0 & - \\
\hline D & 37.4 & 0 & 0 & 0 & 0 & 0 & 0 & 0 & 0 & - \\
\hline Total & & & 458 & 47 & 06 & 256 & 198 & 366 & 509 & 50 \\
\hline
\end{tabular}

With respect to meningitis on the other hand, the data for recorded patients between 2004 and 2011 (Table 3) reflects a high incidence of the disease and fatalities within the peak months of the dry season during which the mean monthly rainfall recorded hardly exceeds $0 \mathrm{~mm}$. It is worth noting the significant fluctuation in temperatures from December to February, where there is a plummet in the temperature from $36.7^{\circ} \mathrm{C}$ in December to $31.4^{\circ} \mathrm{C}$ in January and the sudden rise to $37^{\circ} \mathrm{C}$ in February, $41.9^{\circ} \mathrm{C}$ in March, $45^{\circ} \mathrm{C}$ in April and $41.8^{\circ} \mathrm{C}$ in May. As we get into the heart of the rainy season, there is a remarkable plummet in the number of patients from June to January with recordings of zero patients. Consequently, overall findings reveal that meningitis bacteria are favored by a combination of high temperature with little rainfall and low atmospheric humidity. This is further supported by the pattern reflected on the risk map for epidemic meningitis, for the African continent. Figure 1 shows that the highest risk zones for meningitis spans or conforms with the entire Sahel Belt of Africa. 
Table 3. Number of recorded Meningitis patients from 2004 to 2011 in the Far North Region of Cameroon

\begin{tabular}{|c|c|c|c|c|c|c|c|c|c|c|}
\hline \multirow[t]{2}{*}{ Months } & \multirow{2}{*}{$\begin{array}{l}\text { Mean monthly } \\
\text { Temperature }\end{array}$} & \multirow{2}{*}{$\begin{array}{l}\text { Mean monthly } \\
\text { Rainfall }\end{array}$} & \multicolumn{8}{|c|}{ Recorded number of patients per year } \\
\hline & & & 2004 & 2005 & 2006 & 2007 & 2008 & 2009 & 2010 & 2011 \\
\hline $\mathrm{J}$ & 31.4 & 0 & 0 & 0 & 0 & 0 & 3 & 0 & 1 & 2 \\
\hline $\mathrm{F}$ & 37 & 0 & 10 & 2 & 1 & 2 & 4 & 5 & 11 & 10 \\
\hline M & 41.9 & 0 & 11 & 3 & 8 & 3 & 9 & 9 & 15 & 18 \\
\hline A & 45.6 & 2.5 & 15 & 2 & 8 & 2 & 13 & 4 & 19 & 5 \\
\hline M & 41.8 & 24.5 & 6 & 1 & 0 & 1 & 7 & 2 & 11 & 9 \\
\hline $\mathrm{J}$ & 43.3 & 66.6 & 1 & 0 & 0 & 0 & 0 & 0 & 0 & 0 \\
\hline $\mathrm{J}$ & 41.1 & 193.4 & 0 & 0 & 0 & 0 & 0 & 0 & 0 & 0 \\
\hline A & 38.8 & 204.5 & 0 & 0 & 0 & 0 & 0 & 0 & 0 & 0 \\
\hline $\mathrm{S}$ & 37.8 & 79.9 & 1 & 0 & 2 & 0 & 0 & 0 & 0 & 0 \\
\hline $\mathrm{O}$ & 37.6 & 25.1 & 0 & 0 & 0 & 0 & 0 & 0 & 0 & 0 \\
\hline $\mathrm{N}$ & 37.3 & 0 & 0 & 0 & 0 & 0 & 0 & 0 & 0 & 0 \\
\hline D & 36.7 & 0 & 0 & 0 & 0 & 0 & 0 & 0 & 0 & 0 \\
\hline Total & & & 44 & 08 & 19 & 08 & 36 & 20 & 57 & 46 \\
\hline
\end{tabular}

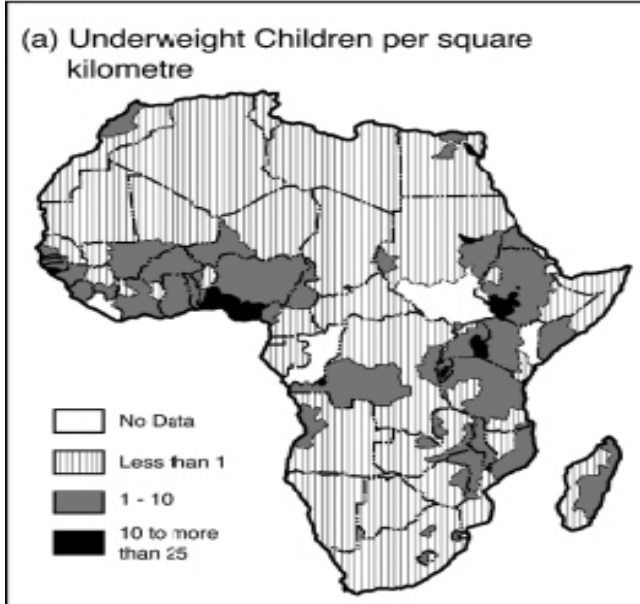

(b) High Mortality Risk

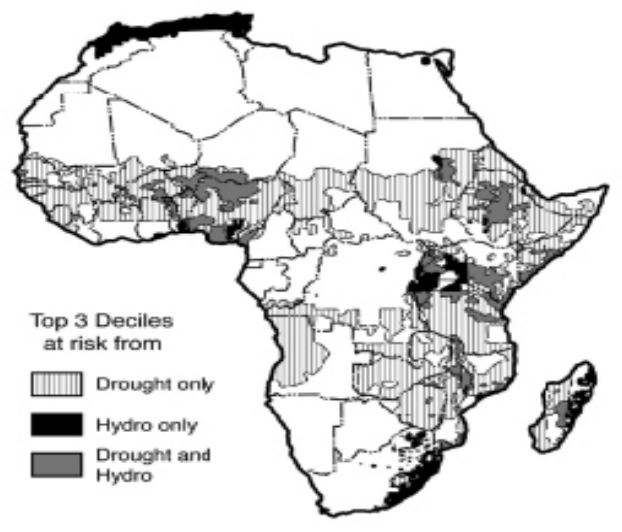

(c) Epidemic Malaria

(d) Epidemic Meningitis
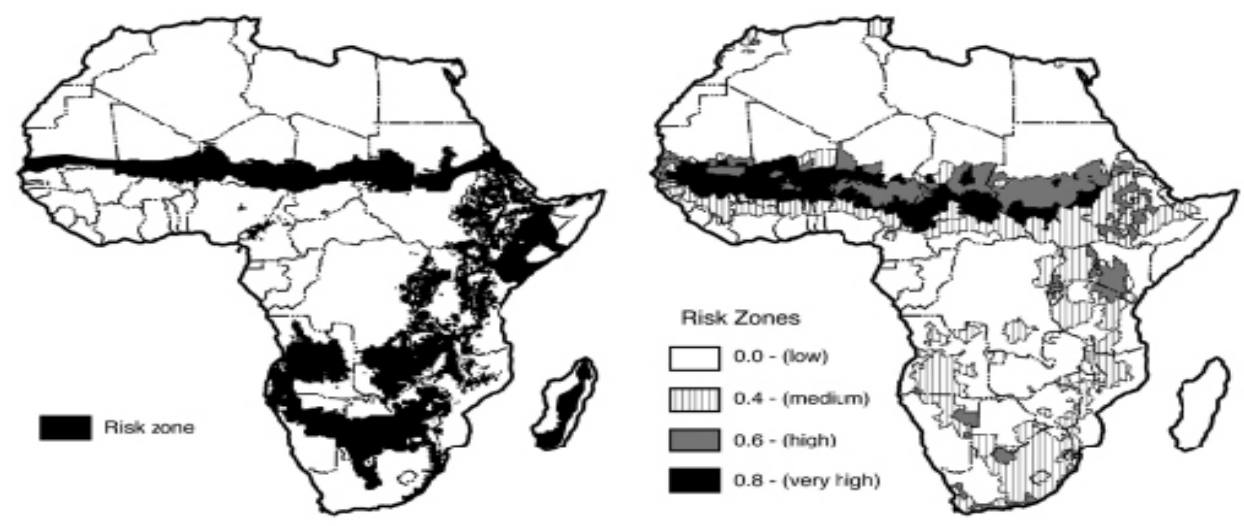

Figure 1. (c) Regions prone to malaria derived from historical rainfall and temperature data (1950-1996); and (d) modeled distribution of districts where epidemics of meningococcal meningitis are likely to occur, based on epidemic experience, relative humidity (1961-1990) and land cover (adapted from IRI et al., 2006) 


\section{Discussions}

Disease ecology from the human perspective means the interactions amongst human beings and their environment, (climate, terrain, and drainage) and the diseases that may result from such interactions. Interactions occur in different proportions and may form or alter habitats for insects or organisms that cause illness. The components of the environment may also directly affect human health that destabilize the physical and mental well-being of man. Vector-borne diseases are of particular interest in disease ecology, as vectors may not survive everywhere but have ideal habitats corresponding approximately to precise geographical realms or biomes. Examples abound and include the over thirty species of the tsetse fly, which live only in tropical Africa, the anopheles mosquito in the tropics, the simulium damnosum in the African Sahel, cholera in congested urban areas, and guinea worm in the tropics. May (1950) (cited in Pyle, 1979) identified two, three and four-factor complexes in disease ecology. These involve the interactions at various stages amongst disease causing agents, vectors, intermediate hosts, reservoirs, and man. These factor complexes are illustrated as follows:

1) Two-factor complex: Host and Agent e.g., bacteria (agent) + man (host) $=$ cholera .

2) Three-factor complex: Host + Agent + Intermediary e.g., protozoa (agent) + mosquito (intermediary host) + man $($ primary host $)=$ malaria .

3) Four-factor complex: Man (primary host) + water (reservoir) + snail (secondary host) + schistosoma (agent) = schistosomiasis.

Disease ecology therefore, involves the interactions of the hosts, agents, vectors, and reservoirs in an environment. Their intensity varies from one ecological unit to another, because the environment in its diversity offers different ranges of tolerance to different organisms. Therefore, organisms have ideal conditions corresponding to specific regions where they can survive and multiply best as provided by latitude, climate, terrain, drainage and vegetation. The creeping of malaria into the colder montane regions of the west and the sporadic manifestation of meningitis in the more humid and less windy environment of the south clearly demonstrate the changing ecology of diseases that could be associated with increasing temperatures, reducing rainfall and expanding aridity. Vulnerability links social and economic structures, cultural norms and values and environmental hazards and disasters in a causative chain. Understanding the vulnerabilities of places and groups of people is an essential first step in mitigating the risks of disasters. This is done through reducing the vulnerability by understanding and underscoring the processes of impoverishment, including climate change events and building resilience in populations as key elements in reducing vulnerability.

Climate variability can be expressed at various temperature scales (by day, season and year) and is an inherent characteristic of climate, whether or not the climatic system is subject to change (Hales et al., 2005). Climate variability has affected many poor countries in Africa and Asia in the last four decades, leading to a scarcity of food and clean drinking water (Huei et al., 2005). Breeding conditions for disease vectors can be favoured by both periods of excessive rainfall and periods of very low or irregular rainfall. The social implication of the health of any displaced population during floods and droughts is an immediate necessity for the sufficient provision of proper nutrition, clean water, public utility and accommodation. The major cholera outbreak in East Africa in 1997 for example, occurred following heavy rains (Hales et al., 2005) as a result of contamination of essential sources of water supply with the faecal wastes

Prolonged dry spells and water scarcity on the other hand would as well enhance major diseases outbreaks especially in poor, hazard-stricken communities or massive refugee camps due to poor hygienic conditions (as a direct result of the unavailability of clean water supplies). Catastrophic floods and droughts which destroy crops can cause food shortages and starvation, malnutrition and an increased risk of infection for any affected population. Flood waters can also create or wash away the breeding grounds for malaria-transmitting mosquitoes. Also worth noting is the influence of high temperatures which result in droughts and the creation of pools of stagnant water, all of which augur well with the breeding conditions of the anopheles mosquito. Similarly, high temperatures have been proven to facilitate the transmission of diarrheal diseases. Time series analysis of diarrheal in the Fiji Islands (1978-1992) for example, confirmed a statistically significant effect of monthly temperature changes - an estimated $3 \%$ increase in diarrheal report per $1{ }^{\circ} \mathrm{C}$ increase in temperature (Hales et al., 2005).

According to the World Meteorological Organization (WMO, 2005), recorded extremes in weather and climate events, such as droughts, tornadoes and high temperatures, continue to occur around the world. Recent scientific evidence indicates that, as global temperatures continue to rise due to climate variation, the number and intensity of extreme events might increase. Climate variation will also affect human health somewhat less directly in the Far North Region of Cameroon by affecting the environment and ecosystems. These indirect effects will occur through insect- and rodent-transmitted diseases. The time frame for the emergence of these health impacts can range from 
weeks to months (for example, an insect-transmitted infection) and from years and decades. The resurgence of cholera, meningitis and other diseases and the links to climate and/or other 'drivers' of change in the Far North Region of Cameroon have recently attracted much attention and debate. There are indications, for example, that in this area more rain is falling than previously experienced. While the factors that predispose populations to meningococcal meningitis are still poorly understood, dryness, very low humidity and dusty conditions need to be taken into account. These factors exist in Far North Region and this explains the recurrence of these diseases in this region as shown on Tables 2 and 3. From field evidence, it was also found out that the wind, particularly in February, March and April account for $85 \%$ of the variation in the number of meningitis cases.

\section{Conclusion}

While infectious diseases such as cholera are being eradicated in other parts of the world, they are re-emerging in Cameroon and Africa in general. A major challenge facing Cameroon and the continent at large is the relative weakness in disease surveillance and reporting systems, which hampers the detection and control of cholera epidemics, and, as a side effect, makes it difficult to obtain the long-term linked data sets on climate and disease that are necessary for the development of early warning systems (WHO, 2005). However, in Cameroon, vigorous debates among those in the health sector have improved our understanding of the links between climate variability (including extreme weather events) and infectious diseases. From the climatic and epidemiological data analyzed, changes in temperature and precipitation could alter the geographical distribution of malaria in the Far North Region and Cameroon at large, with previously unsuitable areas of dense human population becoming suitable for transmission.

Most assessments of health have concentrated on malaria, and there are still debates on the attribution of malaria resurgence in some African countries. The potential for climate variability to intensify or alter flood patterns may become a major additional driver for future health risks from flooding. The need thus arises to examine the impacts of future climate change on other health problems; for example, dengue fever, meningitis and cholera. It is also imperative to begin a dialogue and research effort on the heightened vulnerabilities associated with cholera, meningitis, dengue fever and malaria in the northern region of Cameroon. Furthermore, it is important to enhance the institutional capacity in the various regions in order to provide opportunities for young scientists to improve research in the fields of climate-change vulnerability and adaptation

Perhaps it is worth noting that the populations of the world cities and regions will continue growing at such rapid rates which will go a long way to favour the emergence of problematic living environments for the human race, particularly in Third World Cities. Because an overwhelming majority of the world's population is poor, they will continue their struggle for survival and it is their right to do so even if it means overcrowding and absolutely compromising the aesthetic and environmental qualities of our cities with resultant health implications. As Lambi (2001) noted, 'the people of the underdeveloped nations are now reaching out for their share of the "good things" which the people of the industralised world have enjoyed for a long time'. Climate variability is a natural phenomenon but city environments also make their own local climate. Consequently, effective mitigation against human health-related problems in city environments must emphasize the continuous long term application and monitoring of measures and results through adequate provision of acceptable housing with relevant facilities for proper sanitation and potable water supplies. Consequently, through the initiation and establishment of affordable housing in new layouts, which may not necessarily be within close proximities to present city centres, urban planning, as complex as it is, should be a continuous process, an all time development priority for developing countries.

Consequently, although climate variability is a natural phenomenon, human activities have significantly increased the rates of environmental degradation with some of the most noticeable impact through extremes in climatic phenomena. The general high values for the coefficient of variation reveal the fact that there have been quite frequent and severe anomalies in what should be the regular climatic pattern of temperature and rainfall. Our ingenuity cannot stop nature's processes. However, we can effectively mitigate the effect of these phenomena through the continuous consideration and implementation of acceptable measures for urban and environmental planning, even in the best urban and residential environment. Similarly, the outbreaks of for cholera and meningitis appear to be related to episodes of rainfall excesses (with resultant flooding) and rainfall failures or long and severe dry spell respectively.

\section{References}

Ayonghe, S. N. (2001). A Quantitative Evaluation of Global Warming and Precipitation in Cameroon from 1930 to 1995 and Projections to 2060: Effects on the Environment and Water Resources. In: C. M. Lambi, \& B. E. Eze (Eds.), Reading in Geography. Bamenda, Cameroon: Unique Printers. 
Basilevsky, B. (1994). Statistical Factor Analysis and Related Methods. New York: John Wiley \& Sons. http://dx.doi.org/10.1002/9780470316894

Brown, V., Mohamed, A. I., Maria, R. P. B., \& Andre, P. (1998). Epidemic of malaria in north-eastern Kenya. Lancet, 352, 1356-1357. http://dx.doi.org/10.1016/S0140-6736(05)60747-7

Chan, N., Ebi, K., Smith, F., Wilson, T., \& Smith, A. (1999). An integrated assessment framework for Climate change and infectious diseases. Environ Health Perspect, 107, 329-337. http://dx.doi.org/10.1289/ehp.99107329

Cunningham, P., \& Saigo, W. (1997). Environmental Science: A Global Concern (4th ed.). London/Chicago, UK, USA: Brown Publishers

Cunningham, W. P., \& Cunningham, M. A. (2004). Principles of Environmental Sciences. Inquiry and Applications. London: McGraw Hills.

Department for International Development. (2004). Climate change deepends poverty and challenges poverty reduction strategies. UK.

Dilion, W. R., \& Goldestein, M. (1984). Multivariate Analysis. Methods and Applications. New York: John Wiley $\&$ Sons.

Dinar, A., Hassan, R., Mendelsohn, R., Benhin, J., \& Lambi, C. M. (2003). Climate Change and Agriculture in Africa. Impact Assessment and Adaptation Strategies. London, UK: Earthscan

Goudie, A. (1990). The Human Impact on the Environment ( $3^{\text {rd }}$ ed.). Cambridge: MIT Press.

Hales, S., \& Edwards, S. J. (2005). Impact on health of climate extremes. In: Climate Change and Human health (pp. 79-102). Geneva, Switzerland.

Huei-Ting, T., \& Tru, M. (2005). Effect of global climate on disease epidemics and social instability around the world. In: Hman Security and Climate Change. An International workshop, Holmen Fjord Hotel, Asker, Oslo

Intergovernmental Panel on Climate Change (IPCC). (2001). Summary for policymakers to climate Change. Synthesis report of the IPCC Third Assessment Report, Geneva Switzerland

International Federation of Red Cross and Red Crescent Societies (IFRC). (2009). World disasters report. Geneva Switzerland Intergovernmental Panel on Climate Change (IPCC) (2001a): Climate Change. IPCC third Assessment Report, Geneva Switzerland

Kovats, R. S., Ebi, K., \& Menne, B. (2003). Health and Global Environmental Change. Vol. 1. Methods of Assessing Human Health Vulnerability and Public Health Adaptation to Climate Change, Copenhagen: World Health Organisation, Health Canada, United Nations Environmental Programme. World Meteorological Organisation.

Lambi, C. M. (2001). Revisiting the Environmental Trilogy: Man, Environment and Resources. In: Lambi, (Ed.) Environmental Issues: Problems and Prospects, Uniques Printers, Bamenda, Cameroon

Lorenz, E. N. (1956). Empirical Orthogonal Function and Statistical Weather Prediction. Report 1. Cambridge, M.A. Massachusetts Institute of Technology, Department of Meteorology.

Mabogunje, A. (1986). Urbanisation in Nigeria. London: University of London.

Malakooti, M. A. et al. (1998). Re-emergence of epidemic malaria in the highlands of western Kenya. Emerging Infectious Diseases, 4(4), 671-676. http://dx.doi.org/10.3201/eid0404.980422

May, J. M. (1950). Medical Geography: Its Methods and Objectives. Geographical Review, 40(1), 9-41. http://dx.doi.org/10.2307/210990

McMicheal, A. J., Cambpbell-Lendrum, D. H., Corvalan, C., Ebi, K. I., Githeko, A., \& Scheraga, J. D. (2003). Climate Change and Human Health. Risk and Response, Geneva World Health Organisation/World Meteorological Organisation/ United Nation Environmental Programme.

McMicheal, A. J., Haines, A., Sloff, R., Kovats, S., Ando, M., \& Carcavallo, R. (1996). Climate Change and Human Health. Geneva: World Health Organisation.

McMicheal, A. J., \& Kovats, S. (1999). El Tiempo el clima y la salud (in Spanish) Bol Organ Meteorol Mund.

Ndenecho, E. N., \& Fonteh, M. L. (2012). Fresh Water and Coastal Resource Management in Cameroon: Building Resistance and Resilience to Climate Change. Bamenda, Cameroon: Agwecams Printers. 
Neba, A. (1987). Modern Geography of the Republic of Cameroon ( $2^{\text {nd }}$ ed.). New Jersey: Neba publisher, CAMDEM.

Ngakfumbe, S. N. (2001). Rainfall Probability and Reliability: The Case of Cameroon. In: C. M. Lambi, \& B. E. Eze (Eds), Reading in Geography. Bamenda, Cameroon: Unique Printers.

NIS. (2005). Statistical Yearbook. Yaounde: Ministry of Economy and Finance

Pyle, G. F. (1979). Applied Medical Geography. London: Wiley.

Spore. (Auggust, 2008). Sharing knowledge, improving rural livelihoods.

Timberlake, L. (1986). Africa in Crisis. The causes, the Cures of Environmental bankruptcy. An Earthscan paperback, New Society publishers, Philadelphia, PA, USA.

UNDP. (2004). A Global Report. Reducing Disaster Risk. A Challenge for Development.

WHO. (1998). Cholera in 1997. Weekly Epidemiological Record, 73, 201-208.

WHO. (2005). Using Climate to Predict Diseases outbreaks. A Review. WHO/SDE/OEH/04.01 Geneva. World Health Organisation. 